\title{
Inhibitory Control at a Synaptic Relay
}

\author{
Gautam B. Awatramani, ${ }^{1}$ Rostislav Turecek, ${ }^{2}$ and Laurence 0. Trussell ${ }^{1}$ \\ ${ }^{1}$ Oregon Hearing Research Center/Vollum Institute, Oregon Health and Science University, Portland, Oregon 97239, and ${ }^{2}$ Institute of Experimental \\ Medicine, The Academy of Sciences of the Czech Republic, 11720 Prague 1, Czech Republic
}

The mammalian medial nucleus of the trapezoid body (MNTB) harbors one of the most powerful terminals in the CNS, the calyx of Held. The mechanisms known to regulate this synaptic relay are relatively ineffective. Here, we report the presence of a remarkably robust and fast-acting glycinergic inhibitory system capable of suppressing calyceal transmission.

Evoked glycinergic IPSCs were relatively small in 2-week-old rats, an age by which calyceal maturation has reportedly neared completion. However, by postnatal day 25 (P25), glycinergic transmission had undergone a vigorous transformation, resulting in peak synaptic conductances as high as $280 \mathrm{nS}$. These are comparable with glutamatergic conductances activated by calyceal inputs. Decay kinetics for IPSCs were severalfold faster than for glycinergic synaptic events reported previously. At physiological temperatures in P25 rats, IPSCs decayed in $\sim 1 \mathrm{msec}$ and could be elicited at frequencies up to $500 \mathrm{~Hz}$. Moreover, EPSPs triggered by glutamatergic signals derived from the calyx or simulated by conductance clamp were suppressed when preceded by simulated glycinergic IPSPs. The matching of excitatory transmission in the calyx of Held by a powerful, precision inhibitory system suggests that the relay function of the MNTB may be rapidly modified during sound localization.

Key words: auditory; development; GABA; glycine; inhibition; MNTB

\section{Introduction}

The physiological, biochemical, and biophysical properties of the calyx of Held of rodents have been scrutinized thoroughly over the first few weeks of development. During this period, the synapse develops the capacity to drive medial nucleus of the trapezoid body (MNTB) neurons reliably and at high rates. Just after the onset of hearing [postnatal day 12 (P12)], a variety of specialized proteins, including calcium and potassium channels, calcium-binding proteins, and glutamate receptors, and vesicle stores, reach adult levels of expression (Lohmann and Friauf, 1996; Iwasaki and Takahashi, 1998; Caicedo and Eybalin, 1999; Taschenberger and von Gersdorff, 2000; Lohrke and Friauf, 2002; Taschenberger et al., 2002; Elezgarai et al., 2003). Together, these properties enable the large and rapid excitatory drive that characterizes the MNTB.

Principal neurons of the MNTB sign-invert calyceal signals and relay glycinergic inhibition to various nuclei in the auditory brainstem (Moore and Caspary, 1983). The large calyciform input permits the conservation of temporal precision as excitation is translated to inhibition. The excitatory signal derived from the calyx is faithfully transmitted even at high frequencies $(>600 \mathrm{~Hz})$ (Wu and Kelly, 1993; Taschenberger and von Gersdorff, 2000). However, the invariance of fidelity in the MNTB has been questioned. Extracellular recordings in the cat MNTB has revealed

\footnotetext{
Received Nov. 20, 2003; revised Jan. 27, 2004; accepted Feb. 3, 2004.

This work was supported by National Institutes of Health Grant DC04450. We thank Dr. Tao Lu for advice during this project.

Correspondence should be addressed to Dr. Gautam Awatramani, Oregon Hearing Research Center/Vollum Institute, Mail Code L-335A, 3181 Southwest Sam Jackson Park Road, Portland, OR 97239. E-mail: awatrama@ohsu.edu.

DOI:10.1523/JNEUROSCI.5144-03.2004

Copyright $\odot 2004$ Society for Neuroscience $\quad$ 0270-6474/04/242643-05\$15.00/0
}

spike failures in postsynaptic neurons during high-frequency stimulation (Guinan and Li, 1990). Kopp-Scheinpflug et al. (2003) observed that, in the MNTB of gerbils, certain sound stimulation paradigms led to spike activity in presynaptic axons but not in the principal neurons. These results suggest that excitatory transmission in MNTB may be subject to inhibition, strong enough to offset the massive excitatory input from the calyx. However, this proposition raises a dilemma, because all of the known inhibitory synaptic mechanisms seem ill-suited for overcoming the high safety factor of calyceal transmission (Von Gersdorff et al., 1997; Iwasaki and Takahashi, 2001; Kimura et al., 2003; Leao et al., 2003).

Physiological studies indicate that IPSCs in the immature MNTB are mediated by $\mathrm{GABA}_{\mathrm{A}}$ receptors, which are replaced by glycine receptors in older rats (Banks and Smith, 1992; Awatramani et al., 2003). This switch is synchronized with the maturation of calyceal transmission (Awatramani et al., 2003). However, anatomical studies suggest that the expression of the "adult" glycine receptor subunit $(\alpha 1)$ does not peak until $\sim 3$ weeks after birth (Friauf et al., 1997; Piechotta et al., 2001). This led us to investigate the properties of inhibition in older animals. We found that, in rats older than P20, the glycinergic system becomes profound in its magnitude and kinetics. We evaluated the functional properties of mature glycinergic IPSCs at physiological temperatures and tested its ability to modify glutamatergic signals derived from the calyx.

\section{Materials and Methods}

Slice preparation. Coronal slices of brainstem were prepared from P13P27 rats. Animals were decapitated, the brainstem was dissected, and 200-300 $\mu \mathrm{m}$ sections were cut with a vibratome (VT1000S; Leica, Deerfield, IL). Slices were transferred to an incubation chamber containing a 
$37^{\circ} \mathrm{C}$ extracellular solution (ECS) [in mM: $125 \mathrm{NaCl}, 25$ glucose, $2.5 \mathrm{KCl}$, $1 \mathrm{MgCl}_{2}, 2 \mathrm{CaCl}_{2}, 1.25 \mathrm{NaH}_{2} \mathrm{PO}_{4}, 25 \mathrm{NaHCO}_{3}, 0.4$ ascorbic acid, 3 myoinositol, and 2 sodium pyruvate (bubbled with $5 \% \mathrm{CO}_{2}-95 \% \mathrm{O}_{2}$ for 1 $\mathrm{hr})$ ], after which the chamber was brought to room temperature. Recordings were obtained within $4-5 \mathrm{hr}$ of slicing.

Whole-cell recordings. When ready for use, slices were transferred to a recording chamber and bathed with ECS $\left(21-22^{\circ} \mathrm{C}\right.$ or $\left.36-37^{\circ} \mathrm{C}\right)$ at $2-3$ $\mathrm{ml} / \mathrm{min}$ through a gravity-fed perfusion system. MNTB neurons were viewed using a Zeiss (Oberkochen, Germany) Axioskop-FS equipped with differential interference contrast optics and a $63 \times$ water-immersion objective (Achroplan; Zeiss). Whole-cell voltage-clamp recordings were made from MNTB neurons with an Axopatch 200B amplifier (Axon Instruments, Foster City, CA). Signals were filtered at $5-10 \mathrm{kHz}$ and sampled at $20-100 \mathrm{kHz}$. For recording-evoked IPSCs, patch pipettes (1-2 $\mathrm{M} \Omega$ ) were filled with internal solution containing the following (in mM): $140 \mathrm{CsCl}$, 5 EGTA, $1 \mathrm{MgCl}_{2}$, 10 HEPES, 2 ATP, $0.3 \mathrm{GTP}$, and 10 phosphocreatine, $\mathrm{pH}$ adjusted to 7.3 with $\mathrm{CsOH}$ ( $\sim 300 \mathrm{mOsm})$. Most reagents were obtained from Sigma (St. Louis, MO). QX-314 at $5 \mathrm{~mm}$ (Alomone Labs, Jerusalem, Israel) was added to eliminate postsynaptic action currents. For current-clamp experiments, pipettes were filled with the following (in mM): $145 \mathrm{~K}$-gluconate, $5 \mathrm{KCl}, 1 \mathrm{MgCl}_{2}, 10 \mathrm{HEPES}, 0.05$ EGTA, 2 ATP, 0.3 GTP, and 10 phosphocreatine, pH 7.3. Voltages were corrected for a $13 \mathrm{mV}$ junction potential. The series resistance for recordings was $<3-7 \mathrm{M} \Omega$ a few minutes after whole-cell mode was established but usually increased to a stable value between 7 and $15 \mathrm{M} \Omega$ within 10 min of recording. This was compensated by $70-90 \%$ (lag of $10-20 \mu \mathrm{sec}$ ).

A 50-100 $\mu \mathrm{sec}, 5-50 \mathrm{~V}$ pulse generated through an isolated stimulus unit (Iso-flex; A.M.P.I., Jerusalem, Israel) and delivered via an ECS-filled theta electrode was used to stimulate excitatory or inhibitory axons. The placement and intensity were optimized to obtain the largest IPSCs. IPSCs were recorded in the presence of $10 \mu \mathrm{M}$ 6,7-dinitroquinoxaline2,3-dione (Tocris Cookson, Ballwin, MO) and $100 \mu \mathrm{M}( \pm)$-2-amino-5phosphonopentanoic acid (Research Biomedicals, Natick, MA). Other drugs were added to the perfusate, as indicated: $0.5 \mu \mathrm{M}$ strychnine hydrochloride (Sigma), $10 \mu \mathrm{M}$ SR-95531 (Tocris Cookson), and $0.5 \mu \mathrm{M}$ tetrodotoxin (TTX) (Alomone Labs). Data were collected 3 min after the wash-in of the drug. EPSPs were stimulated in the presence of $0.5 \mu \mathrm{M}$ strychnine. Only if EPSPs were suprathreshold in response to a $500 \mathrm{~Hz}$ train stimulus were they assumed to be healthy calyceal inputs. Simulated inhibitory conductances (IPSGs) were injected with an SM-1 amplifier (Cambridge Conductance, Cambridge, UK). The 10-90\% rise time of the current output in response to a voltage change for this amplifier is 290 nsec. Reversal potentials were set to $-75 \mathrm{mV}$ for IPSGs and zero for EPSGs. Preliminary experiments using gramicidin perforated patches indicate a glycine reversal potential between -75 and $-80 \mathrm{mV}$ in mature MNTBs (G. Awatramani, unpublished observations), so the value we used for the IPSGs would, at worst, underestimate the degree of inhibition.

Data analysis. Evoked IPSCs were analyzed in Clampfit 9.0 (Axon Instruments, Foster City, CA). Spontaneous miniature IPSCs (mIPSCs) were detected using a sliding-template procedure (Axograph 4.0; Axon Instruments). The threshold for detection was set low; noise that met trigger specifications was rejected during visual inspection. Aligned mIPSCs were averaged, and decays were fit by single- or double-exponential function [judged by improvement of the sum of squared errors (SSE)]: $D(t)=A_{1}{ }^{*} e^{-t /} \tau_{\text {fast }}+A_{2}{ }^{*} e^{-t /} \tau_{\text {slow }}$, where $D(t)$ is mIPSC decay as a function of time, $A_{1}$ and $A_{2}$ are amplitude constants, and $\tau_{\text {fast }}$ and $\tau_{\text {slow }}$ are fast and slow decay time constants, respectively. When the SSE of the fit was not significantly improved by adding the second exponent, $A_{2}$ was set to 0 . Results are expressed as mean \pm SEM, and the significance was determined by Student's $t$ test (significance at $p<0.05$ ).

\section{Results}

\section{Increase in glycinergic transmission}

IPSCs were evoked at room temperature after critical placement of the stimulus pipette, usually $\sim 20-200 \mu \mathrm{m}$ from the soma of the recorded neuron. These events were inhibited by $98 \pm 1 \%$ $(\mathrm{P} 16-\mathrm{P} 21 ; n=5)$ by the glycine receptor antagonist strychnine
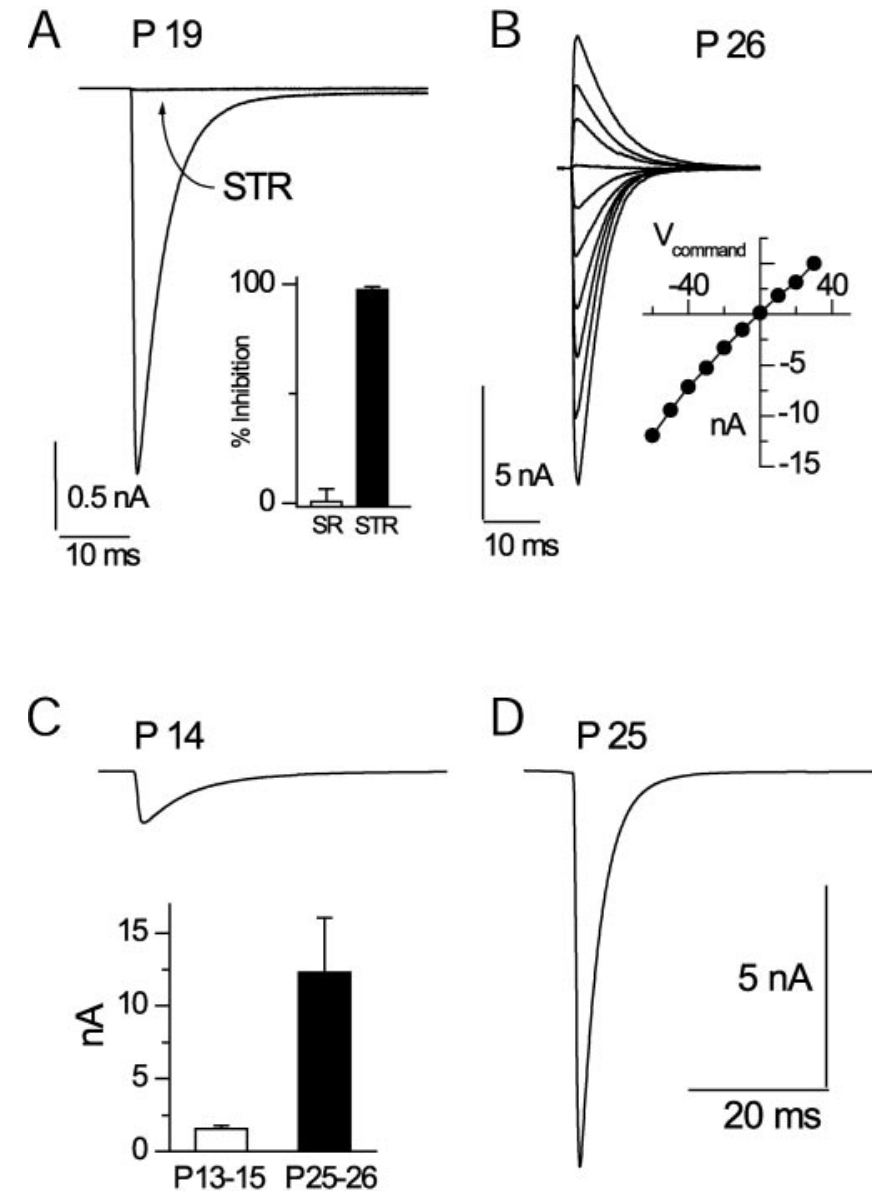

Figure 1. Development of powerful glycinergic IPSCS. A, Nearly complete block of an IPSC in a P19 rat by $0.5 \mu \mathrm{m}$ strychnine. Inset, Percentage block by SR-95531 (SR) and strychnine (STR) for $P 19-P 25$ rats. $B$, Current-voltage relationship for a single IPSC. Voltage range is -60 to $+30 \mathrm{mV}$. C, D, Examples of IPSCs from P14 and P25 rats, respectively. Inset in C shows average data for the indicated ages. Calibration in $D$ applies also to $C$.

$(0.5 \mu \mathrm{M})$. In addition, IPSCs were insensitive to $10 \mu \mathrm{M}$ of the $\mathrm{GABA}_{\mathrm{A}}$ receptor antagonist SR-95531 ( $1 \pm 6 \%$ inhibition; $\left.n=5\right)$ (Fig. 1A). Therefore, IPSCs were considered glycinergic (Jonas et al., 1998).

Glycinergic events in older animals (P25-P26) were very large. In $\mathrm{Cl}^{-}$-loaded cells at $-70 \mathrm{mV}$, these events averaged $12.3 \pm 3.8$ $\mathrm{nA}(n=4)$ (Fig. $1 C, D)$. Moreover, the current-voltage relationship was linear $(r=0.99)$, suggesting that the responses were not significantly contaminated by active conductances (Fig. $1 B$ ). Miniature IPSCs measured in the presence of TTX were also large at these ages $(295 \pm 37 \mathrm{pA} ; n=10)$. In contrast, in P13-P15 rats, an age when calyceal transmission is nearly mature (Taschenberger and von Gersdorff, 2000; Iwasaki and Takahashi 2001; Taschenberger et al., 2002), the average evoked and miniature IPSCs were $1.5 \pm 0.2 \mathrm{nA}(n=20)$ and $128 \pm 20 \mathrm{pA}$ (1025 events; $n=7$ ), respectively (Fig. $1 C$ ). Thus, the development of the glycinergic system is apparently delayed with respect to excitation and the onset of hearing (at approximately P12 in rats) (Blatchley et al., 1987).

The decay time course of the IPSC was estimated by fitting to a double-exponential function. In P25-P26 rats, the IPSCs had an average $\tau_{\text {fast }}$ of $2.9 \pm 0.3 \mathrm{msec}$ ( $96 \%$ of the fit) and a $\tau_{\text {slow }}$ of $12.3 \pm$ $16.4 \mathrm{msec}$. Miniature IPSCs also had similar kinetics, and doubleexponential fits revealed a fast exponential ( $99 \%$ contribution) of $2.1 \pm 0.1 \mathrm{msec}(n=2000$ events, 10 cells $)$. 

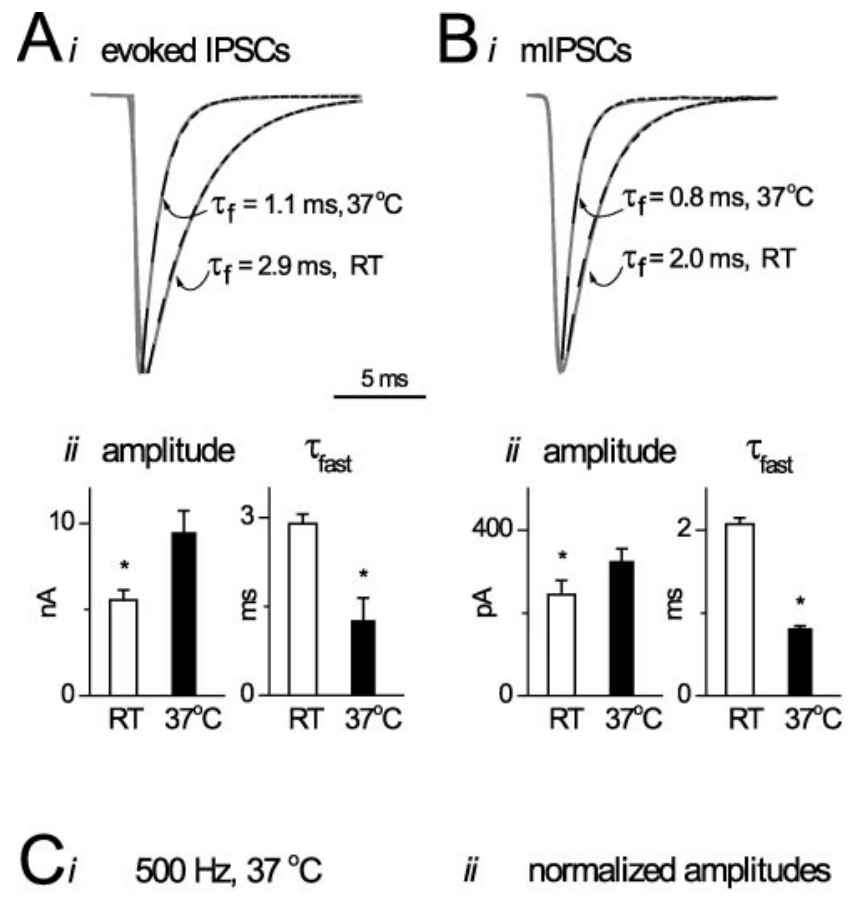

$500 \mathrm{~Hz}, 37^{\circ} \mathrm{C}$

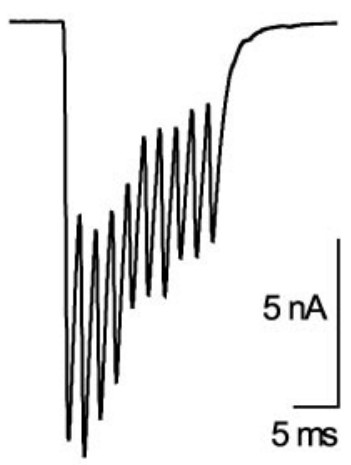

ii normalized amplitudes

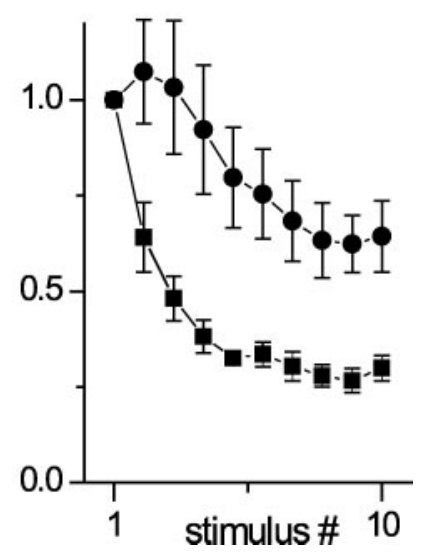

Figure 2. IPSCs at physiological temperatures. Ai, Examples of evoked IPSCs at room temperature (RT) versus $37^{\circ}$. Exponential fits to decays are shown with dominant time constants indicated. Aii shows mean amplitude and decay constants for evoked events at two temperatures. Bi, Bii, Examples and average data for mIPSCs at room temperature and $37^{\circ} \mathrm{C}$. Ci, Example of IPSCs evoked at $500 \mathrm{~Hz}$. Cii, Average data for four neurons showing peak (circles) and baseline currents (squares) during a train of 10 stimuli at $500 \mathrm{~Hz}$.

\section{IPSCs at physiological temperatures}

To assess the potential effectiveness of glycinergic transmission, we measured the properties of evoked and mIPSCs at $36-37^{\circ} \mathrm{C}$ in P22-P27 rats. As shown in Figure $2 B$, glycinergic mIPSCs were twice as fast as those measured at room temperature $\left(\tau_{\text {fast }}=0.8 \pm\right.$ $0.2 \mathrm{msec})$. The evoked IPSCs were also briefer at $37^{\circ} \mathrm{C}\left(\tau_{\text {fast }}=\right.$ $1.0 \pm 0.2 \mathrm{msec}$ ) (Fig. $2 \mathrm{~A}$ ). The close correspondence in the kinetics of the evoked and mIPSC suggest that quantal release is extremely synchronous.

Because neurons in MNTB respond to sound with bursts of activity, we evoked IPSCs with short trains of high-frequency stimuli. IPSCs could be elicited at frequencies up to $500 \mathrm{~Hz}$ without failures. At this frequency, the IPSCs did not fully decay to baseline between stimuli, generating a "tonic" current. To quantify these responses, we measured absolute and relative peak (absolute amplitude-tonic current) of each IPSC in the trains (Fig. $2 C)$. Although there was marked synaptic depression in response
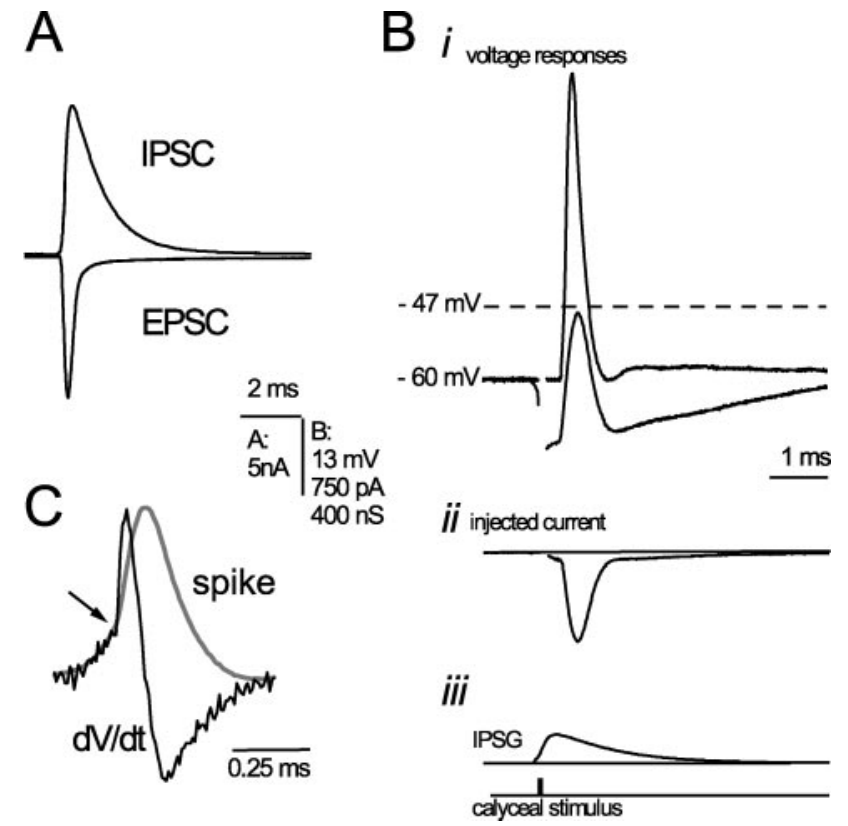

Figure 3. Electrical interaction between glutamatergic and glycinergic signals. $A$, Examples illustrating the relative size of IPSCs and EPSCs for equivalent absolute driving force. Bi-Biii, Shunting of calyceal EPSP by simulated IPSG. Bi, A suprathreshold and a shunted EPSP. Bii, The injected current from the conductance clamp. Biii, The conductance waveform and timing of synaptic stimulus. Dashed line indicates spike threshold. C, An action potential (gray trace) scaled and superimposed on its first derivative (black). Arrow indicates the point of inflection at which an EPSP gives rise to a spike and is accentuated by the sudden change in derivative slope. Voltage at this point was defined as threshold.

to $500 \mathrm{~Hz}$ stimuli and the relative amplitude of the 10th IPSC was $\sim 40 \%$ of the first, the absolute amplitude of the 10th response was still $>55 \%$ of the first IPSC. Hence, the combination of phasic and tonic currents gives rise to a potent inhibitory signal during trains of responses.

\section{Conductance-clamp studies}

Are these inhibitory responses sufficient to shunt calyceal excitatory signals? Figure $3 A$ compares an IPSC and EPSC (mean EPSC at $-70 \mathrm{mV}, 10.7 \pm 0.8 \mathrm{nA}$ ) (Taschenberger and von Gersdorff, 2000), revealing comparable amplitude currents for identical driving force. The relative strength of excitatory and inhibitory signals was tested by injecting inhibitory conductances of varying amplitudes during synaptically evoked EPSPs derived from the calyx. Figure $3 \mathrm{Bi}$ shows an example of the robust voltage response of an MNTB neuron to calyceal stimulation. The spike was effectively shunted when an inhibitory conductance of $200 \mathrm{nS}$ was injected just before the onset of the excitatory response. This value was within the range of conductances measured in the oldest group of rats (60-285 nS). The dashed line indicates spike threshold for this neuron (see below). Figure 3 Bii illustrates the inhibitory current injected into the cell. Shunting was considered in terms of the effectiveness of action-potential generation. Spike threshold was defined as the voltage at which an inflection in the rising phase of the EPSP was visible. This was accentuated by taking a derivative of the voltage trace, as in Figure $3 C$. In most cases, it was necessary to deliver several EPSPs at high frequency to reduce their amplitude sufficiently to resolve this inflection point. In six experiments, threshold was $-50 \pm 1 \mathrm{mV}$ (range, -53 to $-47 \mathrm{mV}$; resting potentials were $-67 \pm 1 \mathrm{mV}$ ). In five experiments, graded EPSGs were delivered using conductance clamp; these yielded an estimate of threshold of $-52 \pm 2 \mathrm{mV}$. In 
five experiments using low-frequency calyceal stimuli, the average spike probability (normally 1.0 ) was $0.5 \pm 0.1$ with inhibition. In an alternative approach to testing inhibition, $200 \mathrm{nS}$ IPSGs rendered subthreshold the response of the MNTB neuron to 60-180 nS simulated EPSGs $(n=6)$. Hence, the magnitude and time course of the glycinergic conductance appears adequate to inhibit calyceal signaling.

\section{Discussion}

\section{Glycinergic transmission in MNTB}

The magnitude and kinetics of glycinergic transmission in mature MNTBs is unparalleled. The exponential decay time for glycinergic mIPSCs measured here $(\sim 2 \mathrm{msec}$ at room temperature and $\sim 0.8 \mathrm{msec}$ at $37^{\circ} \mathrm{C}$ ) is several times faster than those measured previously for glycinergic signals. In comparison, the $\tau_{d}$ values of glycinergic unitary IPSCs measured at room temperature in the retina (Protti et al., 1997), spinal cord (Keller et al., 2001), brainstem motor (Singer et al., 1998), zebrafish Mauthner neurons (Legendre, 1998), immature medial superior olive (MSO) (Smith et al., 2000), and MNTB neurons (Lim et al., 2003) range from $\sim 4$ to $\sim 50 \mathrm{msec}$. Evoked IPSCs were $\sim 10 \times$ larger than those observed in other auditory preparations (Smith and Forsythe, 2000; Lim et al., 2003) and could be elicited at high frequencies with relatively little depression. Together, these properties of glycinergic transmission suggest that it is well suited for modifying excitation with temporal precision. Given that IPSC decay kinetics at room temperature also exceeded those reported for receptors in patches excised from neurons (Singer and Berger, 1999; Ali et al., 2000) or from cells expressing human or zebrafish $\alpha 1$ subunits (Fucile et al., 1999; Gentet and Clements, 2002) or $\alpha 2$ subunits (Mangin et al., 2003), it seems likely that the receptors in mature MNTB contain a novel subunit or posttranslational modification.

\section{Inhibition in auditory brainstem}

The auditory systems of birds and mammals may have evolved independently (Clack, 1997). However, there are remarkable similarities in the circuitries that process information in the temporal domain (Carr and Friedman, 1999; Oertel, 1999). A variety of molecules mediate fast excitatory transmission, including $\mathrm{Kv}$ channels, calcium-buffering proteins, and AMPA receptors, and are similar among birds and mammals. In contrast, the inhibitory systems appear to be divergent in several respects. First, birds use more slowly gating $\mathrm{GABA}_{\mathrm{A}}$ receptors (Yang et al., 1999), whereas inhibition is mediated by both $\mathrm{GABA}_{\mathrm{A}}$ and glycine receptors in mammalian auditory brainstem. Another striking difference is in the $\mathrm{Cl}^{-}$gradient maintained across the cell membrane. In birds, $\mathrm{E}_{\mathrm{Cl}-}$ is far above spike threshold (Hyson et al., 1995; Lu and Trussell, 2001), causing GABA to be excitatory or inhibitory depending on the context of activation (Monsivais et al., 2000; Lu and Trussell, 2001). In mature mammals, the $\mathrm{E}_{\mathrm{Cl}-}$ is usually near or below the resting potential, and GABA and glycine exert a more conventional inhibition. Lastly, during high-frequency activation, GABAergic axons in birds switch into an "asynchronous" mode of release, causing a tonic depolarization of postsynaptic neurons ( $\mathrm{Lu}$ and Trussell, 2000). In contrast, inhibitory axons in mammals follow high-frequency stimuli (Fig. 2) (Needham and Paolini, 2003), promoting phasic inhibition. It is remarkable that such divergent inhibitory systems both play pivotal roles in the sound localization.

Although well timed inhibition has been hypothesized to play an important role in auditory processing (Batra and Fitzpatrick, 1997; Brand et al., 2002; Needham and Paolini, 2003), the kinetics of glycinergic signaling in mature animals is unknown. Brand et al. (2002) demonstrated that the increase in the discharge rate of MSO neurons induced by the application of strychnine was dependent on the interaural time difference (ITD) of the sound stimuli (i.e., it shifted the ITD tuning curve along the abscissa). Models explaining these results rely on the novel presumption that glycinergic inhibition must decay in the microsecond range and be evoked at high frequency (Brand et al., 2002). In this paper, we demonstrate that glycinergic IPSCs of auditory neurons may have kinetic properties consistent with this role.

\section{A modulated synaptic relay at the MNTB}

The MNTB is often viewed solely as a relay station ( Wu and Kelly, 1993; Sommer et al., 1993; Taschenberger and von Gersdorff, 2000). It was thus surprising to find that this nucleus was subject to powerful glycinergic inhibition. Deciphering the inhibitory circuitry in the superior olivary complex has proven difficult, because a number of nuclear groups are in close apposition. However, inhibitory axons projecting to the MNTB are capable of high-frequency transmission, suggesting that inhibition might arise from nuclei in which temporal information is preserved. Recurrent collaterals in the MNTB are one possible source of inhibition (Kuwabara et al., 1991). The ventral and lateral nuclei of the trapezoid body also receive large inputs from spherical and globular bushy cells with temporal precision and are therefore potential sources of inhibition.

The MNTB provides well timed inhibition to the MSO and lateral superior olive, crucial for sound localization. Therefore, glycinergic modulation of MNTB activity could have profound consequences. Kopp-Scheinpflug et al. (2003) suggest that "sideband" inhibition could block calyceal transmission postsynaptically. Our studies demonstrate that inhibitory conductances can indeed match the excitatory drive from the calyx and effectively shunt the MNTB neuron. However, the large magnitude of the inhibitory conductance required to do so would have to arise from the near-synchronous excitation of several inhibitory neurons. The situation may be quite different during bursts of activity. Not only do IPSCs depress less than EPSCs, but also their slow kinetics causes them to summate in a frequency-dependent manner. Hence, the ratio of inhibitory to excitatory conductance would get larger during a burst of activity, thus making inhibition more effective.

Diverse mechanisms are known to modulate glutamate release from the calyx (Trussell, 2002). For example, presynaptic of glycine and $\mathrm{GABA}_{\mathrm{A}}$ receptors facilitate release (Turecek and Trussell, 2001, 2002), whereas metabotropic GABA (Takahashi et al., 1998), glutamate (Takahashi et al., 1996), adenosine (Kimura et al., 2003), and noradrenaline receptors (Leao and Von Gersdorff, 2002) suppress release. By themselves, modulatory systems in the MNTB may have little impact on the reliability or timing of calyceal transmission. However, their effectiveness may become apparent in the context of the glycinergic transmission we describe here. Thus, presynaptic modulators may act in synergy with the postsynaptic glycinergic IPSPs to enhance or diminish excitatory transmission.

\section{References}

Ali DW, Drapeau P, Legendre P (2000) Development of spontaneous glycinergic currents in the Mauthner neuron of the zebrafish embryo. J Neurophysiol 84:1726-1736.

Awatramani GB, Lu T, Turecek R, Trussell LO (2003) Development of GABA- and glycinergic transmission in the MNTB. Soc Neurosci Abstr 29:387.12.

Banks MI, Smith PH (1992) Intracellular recordings from neurobiotin- 
labeled cells in brain slices of the rat medial nucleus of the trapezoid body. J Neurosci 12:2819-2837.

Batra R, Fitzpatrick DC (1997) Neurons sensitive to interaural temporal disparities in the medial part of the ventral nucleus of the lateral lemniscus. J Neurophysiol 78:511-515.

Blatchley BJ, Cooper WA, Coleman JR (1987) Development of auditory brainstem response to tone pip stimuli in the rat. Brain Res 429:75-84.

Brand A, Behrend O, Marquardt T, McAlpine D, Grothe B (2002) Precise inhibition is essential for microsecond interaural time difference coding. Nature 417:543-547.

Caicedo A, Eybalin M (1999) Glutamate receptor phenotypes in the auditory brainstem and mid-brain of the developing rat. Eur J Neurosci 11:51-74.

Carr CE, Friedman MA (1999) Evolution of time coding systems. Neural Comput 11:1-20.

Clack JA (1997) The evolution of tetrapod ears and the fossil record. Brain Behav Evol 50:198-212.

Elezgarai I, Diez J, Puente N, Azkue JJ, Benitez R, Bilbao A, Knopfel T, Donate-Oliver F, Grandes P (2003) Subcellular localization of the voltage-dependent potassium channel Kv3.1b in postnatal and adult rat medial nucleus of the trapezoid body. Neuroscience 118:889-898.

Friauf E, Hammerschmidt B, Kirsch J (1997) Development of adult-type inhibitory glycine receptors in the central auditory system of rats. J Comp Neurol 385:117-134.

Fucile S, de Saint Jan D, David-Watine B, Korn H, Bregestovski P (1999) Comparison of glycine and GABA actions on the zebrafish homomeric glycine receptor. J Physiol (Lond) 517:369-383.

Gentet LJ, Clements JD (2002) Binding site stoichiometry and the effects of phosphorylation on human alphal homomeric glycine receptors. J Physiol (Lond) 544:97-106.

Guinan Jr JJ, Li RY (1990) Signal processing in brainstem auditory neurons which receive giant endings (calyces of Held) in the medial nucleus of the trapezoid body of the cat. Hear Res 49:321-334.

Hyson RL, Reyes AD, Rubel EW (1995) A depolarizing inhibitory response to GABA in brainstem auditory neurons of the chick. Brain Res 677:117-126.

Iwasaki S, Takahashi T (1998) Developmental changes in calcium channel types mediating synaptic transmission in rat auditory brainstem. J Physiol (Lond) 509:419-423.

Iwasaki S, Takahashi T (2001) Developmental regulation of transmitter release at the calyx of Held in rat auditory brainstem. J Physiol (Lond) 534:861-871.

Jonas P, Bischofberger J, Sandkuhler J (1998) Corelease of two fast neurotransmitters at a central synapse. Science 281:419-424.

Keller AF, Coull JA, Chery N, Poisbeau P, De Koninck Y (2001) Regionspecific developmental specialization of GABA-glycine cosynapses in laminas I-II of the rat spinal dorsal horn. J Neurosci 21:7871-7880.

Kimura M, Saitoh N, Takahashi T (2003) Adenosine Al receptor-mediated presynaptic inhibition at the calyx of Held of immature rats. J Physiol (Lond) 553:415-426.

Kopp-Scheinpflug C, Lippe WR, Dorrscheidt GJ, Rubsamen R (2003) The medial nucleus of the trapezoid body in the gerbil is more than a relay: comparison of pre- and postsynaptic activity. J Assoc Res Otolaryngol $4: 1-23$.

Kuwabara N, DiCaprio RA, Zook JM (1991) Afferents to the medial nucleus of the trapezoid body and their collateral projections. J Comp Neurol 314:684-706.

Leao RM, Von Gersdorff H (2002) Noradrenaline increases high-frequency firing at the calyx of held synapse during development by inhibiting glutamate release. J Neurophysiol 87:2297-2306.

Leao RN, Oleskevich S, Sun H, Bautista M, Fyffe RE, Walmsley B (2003) Differences in glycinergic mIPSCs in the auditory brainstem of congenitally deaf and normal neonatal mice. J Neurophysiol 91:1006-1012.

Legendre P (1998) A reluctant gating mode of glycine receptor channels determines the time course of inhibitory miniature synaptic events in zebrafish hindbrain neurons. J Neurosci 18:2856-2870.

Lim R, Oleskevich S, Few AP, Leao RN, Walmsley B (2003) Glycinergic mIPSCs in mouse and rat brainstem auditory nuclei: modulation by ruthenium red and the role of calcium stores. J Physiol (Lond) 546:691-699.
Lohmann C, Friauf E (1996) Distribution of the calcium-binding proteins parvalbumin and calretinin in the auditory brainstem of adult and developing rats. J Comp Neurol 367:90-109.

Lohrke S, Friauf E (2002) Developmental distribution of the glutamate receptor subunits KA2, GluR6/7, and delta 1/2 in the rat medial nucleus of the trapezoid body. A quantitative image analysis. Cell Tissue Res 308:19-33.

Lu T, Trussell LO (2000) Inhibitory transmission mediated by asynchronous transmitter release. Neuron 26:683-694.

Lu T, Trussell LO (2001) Mixed excitatory and inhibitory GABA-mediated transmission in chick cochlear nucleus. J Physiol (Lond) 535:125-131.

Mangin JM, Baloul M, Prado De Carvalho L, Rogister B, Rigo JM, Legendre P (2003) Kinetics properties of the \{alpha\}2 homo-oligomeric glycine receptor impairs a proper synaptic functioning. J Physiol (Lond) 553:369-386.

Monsivais P, Yang L, Rubel EW (2000) GABAergic inhibition in nucleus magnocellularis: implications for phase locking in the avian auditory brainstem. J Neurosci 20:2954-2963.

Moore MJ, Caspary DM (1983) Strychnine blocks binaural inhibition in lateral superior olivary neurons. J Neurosci 3:237-242.

Needham K, Paolini AG (2003) Fast inhibition underlies the transmission of auditory information between cochlear nuclei. J Neurosci 23:6357-6361.

Oertel D (1999) The role of timing in the brain stem auditory nuclei of vertebrates. Annu Rev Physiol 61:497-519.

Piechotta K, Weth F, Harvey RJ, Friauf E (2001) Localization of rat glycine receptor alpha1 and alpha2 subunit transcripts in the developing auditory brainstem. J Comp Neurol 438:336-352.

Protti DA, Gerschenfeld HM, Llano I (1997) GABAergic and glycinergic IPSCs in ganglion cells of rat retinal slices. J Neurosci 17:6075-6085.

Singer JH, Berger AJ (1999) Contribution of single-channel properties to the time course and amplitude variance of quantal glycine currents recorded in rat motoneurons. J Neurophysiol 81:1608-1616.

Singer JH, Talley EM, Bayliss DA, Berger AJ (1998) Development of glycinergic synaptic transmission to rat brain stem motoneurons. J Neurophysiol 80:2608-2620.

Smith AJ, Owens S, Forsythe ID (2000) Characterisation of inhibitory and excitatory postsynaptic currents of the rat medial superior olive. J Physiol (Lond) 529:681-698

Sommer I, Lingenhohl K, Friauf E (1993) Principal cells of the rat medial nucleus of the trapezoid body: an intracellular in vivo study of their physiology and morphology. Exp Brain Res 95:223-239.

Takahashi T, Forsythe ID, Tsujimoto T, Barnes-Davies M, Onodera K (1996) Presynaptic calcium current modulation by a metabotropic glutamate receptor. Science 274:594-597.

Takahashi T, Kajikawa Y, Tsujimoto T (1998) G-Protein-coupled modulation of presynaptic calcium currents and transmitter release by a $\mathrm{GABA}_{\mathrm{B}}$ receptor. J Neurosci 18:3138-3146.

Taschenberger H, von Gersdorff H (2000) Fine-tuning an auditory synapse for speed and fidelity: developmental changes in presynaptic waveform, EPSC kinetics, and synaptic plasticity. J Neurosci 20:9162-9173.

Taschenberger H, Leao RM, Rowland KC, Spirou GA, von Gersdorff H (2002) Optimizing synaptic architecture and efficiency for high-frequency transmission. Neuron 36:1127-1143.

Trussell LO (2002) Modulation of transmitter release at giant synapses of the auditory system. Curr Opin Neurobiol 12:400-404.

Turecek R, Trussell LO (2001) Presynaptic glycine receptors enhance transmitter release at a mammalian central synapse. Nature 411:587-590.

Turecek R, Trussell LO (2002) Reciprocal developmental regulation of presynaptic ionotropic receptors. Proc Natl Acad Sci USA 99:13884-13889.

von Gersdorff H, Schneggenburger R, Weis S, Neher E (1997) Presynaptic depression at a calyx synapse: the small contribution of metabotropic glutamate receptors. J Neurosci 17:8137-8146.

Wu SH, Kelly JB (1993) Response of neurons in the lateral superior olive and medial nucleus of the trapezoid body to repetitive stimulation: intracellular and extracellular recordings from mouse brain slice. Hear Res 68:189-201.

Yang L, Monsivais P, Rubel EW (1999) The superior olivary nucleus and its influence on nucleus laminaris: a source of inhibitory feedback for coincidence detection in the avian auditory brainstem. J Neurosci 19:23132325. 